\title{
Low Temperature Synthesis and Surface Modification of High Surface Area Calcium Hydroxyapatite Nano-rods Incorporating Organofunctionalized Surfaces
}

\author{
Aneela Anwar a,b*, Ihtesham U. Rehman ${ }^{\mathrm{c}}$ and Jawwad A Darr ${ }^{\mathrm{a}^{*}}$ \\ ${ }^{a}$ Department of Chemistry, University College London, 20 Gordon Street, London \\ WC1H 0AJ, UK \\ ${ }^{\mathrm{b}}$ Department of Basic Sciences and Humanities, University of Engineering and \\ Technology, KSK Campus, GT Road, Lahore, 39020, Pakistan. \\ c Department of Materials Science and Engineering, Kroto Research Institute, \\ University of Sheffield, North Campus, Broad Lane, Sheffield, S3 7HQ, UK
}

\begin{abstract}
A new low temperature continuous approach for the surface modification of hydroxyapatite (HA), is described. In this method, the HA particle surfaces were modified using methacrylic acid, vinylphosphonic acid, adipic acid, citric acid or polyvinyalcohol, respectively, using a continuous plastic flow synthesis (CPFS) system at a reaction temperature of $70{ }^{\circ} \mathrm{C}$ for 5 minutes. The materials were investigated using a range of analytical techniques, including TEM (Transmission Electron Microscopy), zeta potential, XRD, (X-ray diffraction), BET (BrunauerEmmett-Teller) surface area analysis, FTIR (Fourier Transform Infrared) spectroscopy and XPS (X-ray Photoelectron Spectroscopy). The presence of organic agents in the reagents, resulted in a significant reduction in particle size of the nanoHA rods; TEM studies confirmed the formation of highly dispersed nano-rods of HA with average lengths and diameters in the ranges 20 to $60 \mathrm{~nm}$ and 4 to $10 \mathrm{~nm}$, respectively. XPS analyses suggested that the Ca:P molar ratio decreased from 1.67
\end{abstract}


to ca. 1.34 by the addition of organic surface agents. The zeta potential measurements revealed that the colloidal stability of surface modified HA, generally increased the stability of nanoparticles in water (under certain conditions) compared to ungrafted HA. Therefore, the small size and presence of functional groups, makes these materials potentially suitable for dental restoration fillers and composite bone regeneration applications.

\section{Introduction}

Hydroxyapatite $\left[\mathrm{HA}, \mathrm{Ca}_{10}\left(\mathrm{PO}_{4}\right)_{6}(\mathrm{OH})_{2}\right]$ is a synthetic bone substitute material that has a range of applications in the fields of dentistry and regenerative medicine for example as bulk defect bone fillers, as a reinforcement material in biomedical composites, as a biocompatible coating on implants, and as a component in bone and dental cements ${ }^{1-5}$. Synthetic HA chemically resembles the biological apatite found in natural teeth and bone, and this can be exploited for biomedical applications ${ }^{6-8}$. In particular, HA in nanocrystalline form, is of interest in bone replacement ceramics or composites, because of its hardness, ease with which it can be sintered to high density $^{9}$ and its potential to be incorporated into hybrid biomaterials.

Surface modification of HA by functionalised organic molecules or polymers, provides a way to control the size and surface properties. There are two common procedures to functionalize HA using organic agents. The first method is surface adsorption; indeed many proteins and polymers can be adsorbed onto the surface of $\mathrm{HA}^{10}$. Secondly, surface grafting of organic reactive agents through strong covalent bonding; such particles have applications in the field of HA/polymer composites, column chromatography of proteins, cell culture carrier and as catalyst support materials $^{9,11,12}$. 
Pure stoichiometric synthetic HA can be modified to have a large amount of $\mathrm{P}-\mathrm{OH}$ groups on the surface of particles, therefore, a number of organic or/and inorganic substances have been introduced to $\mathrm{HA}$ surfaces via the $\mathrm{P}-\mathrm{OH}$ functionality. Increasing the number of surface $\mathrm{P}-\mathrm{OH}$ groups is of interest because they can act as anionic surface charges that offers a favorable environment for protein adsorption. Furthermore, increased numbers of $\mathrm{P}-\mathrm{OH}$ groups, can lead to increased electrophoretic mobility and good dispersibility in an aqueous phase (via the charge stabilization mechanism) ${ }^{2,13-18}$. For the synthesis of HA and other bioceramics, the method and conditions of preparation, greatly influences the final properties, nature and crystallinity of the precipitated powder. Reaction parameters for synthesis are important, such as temperature, $\mathrm{pH}$, time as well as aging time, variation in initial $\mathrm{Ca}: \mathrm{P}$ ratio, concentration, mixing dynamics and choice of precursor, etc. ${ }^{19-21}$.

(a)<smiles>C=C(C)C(=O)O</smiles>

(c)<smiles>C=CP(=O)(O)O</smiles>

(d)<smiles>O=C(O)CC(O)(CC(=O)O)C(=O)O</smiles>

Fig. 1 Surface agents used for modification of hydroxyapatite: (a) methacrylic acid, (b) adipic acid, (c) vinylphosphonic acid, (d) citric acid.

Various methodologies have been used for the synthesis of HA powders and coatings including: spray pyrolysis ${ }^{22}$, sol-gel processes ${ }^{23}$, solid state syntheses ${ }^{24}$, 
chemical vapour deposition ${ }^{25}$, solvothermal processes ${ }^{26}$ and wet precipitation methods ${ }^{12,27}$. The majority of the synthesis methods reported in literature for HA production, are multi-step, inconsistent, energy intensive or time consuming processes ${ }^{28-33}$ and almost always involve the need to have careful control over reaction $\mathrm{pH}$ during the mixing of reagents. Recently, the synthesis of HA using the continuous hydrothermal flow synthesis (CHFS) under supercritical conditions of high temperature and pressure $\left(400{ }^{\circ} \mathrm{C}\right.$ and $\left.24 \mathrm{MPa}\right)$, was reported ${ }^{34}$. Due to the high temperatures used therein (and extensive Ostwald ripening), HA produced by continuous hydrothermal flow processes, is similar in size to that obtained using more conventional batch routes. Methods to produce even smaller (functionalised) HA particles are desirable, as they may open up new applications, e.g. those requiring rapid dissolution of HA in vitro, as injectables, or as nano-sized hard filler components for bone replacement and dental restoration composites, including HAs that can possibly form covalent bonds to a polymer phase.

The main objective of the present study was to develop surface-modified nano hydroxyapatites using a facile, low cost, energy efficient and relatively low temperature direct route. These surface modified nano-HAs were extensively characterized and subsequently assessed for the colloidal stability using zeta potential measurements.

\section{Experimental}

\subsection{Materials}

Calcium nitrate tetrahydrate $\left[\mathrm{Ca}\left(\mathrm{NO}_{3}\right)_{2} .4 \mathrm{H}_{2} \mathrm{O}, 99 \%\right]$ and diammonium hydrogen phosphate $\left[\left(\mathrm{NH}_{4}\right)_{2} \mathrm{HPO}_{4}, 98 \%\right]$ and methacrylic acid $(99+\%)$ were purchased from Alpha Aesar, UK. Polyvinylacohol (87-90\%), adipic acid (99\%), citric acid (99\%) 
and vinyl phosphonic acid $\left[\mathrm{CH}_{2}=\mathrm{CHP}(\mathrm{O})(\mathrm{OH})_{2}, 97 \%\right]$ were purchased from Sigma Aldrich (Dorset, UK). Ammonium hydroxide solution $\left(\mathrm{NH}_{4} \mathrm{OH}, 28 \%\right)$ was supplied by VWR International (UK).

\subsection{Synthesis Methodology}

\subsubsection{Synthesis of nano-hydroxyapatite}

Nano-hydroxyapatite (HA) was prepared using a simple continuous plastic flow synthesis (CPFS) system. In this method, 0.3 M diammonium hydrogen phosphate solution and $0.5 \mathrm{M}$ calcium nitrate solutions were pumped in the CPFS (Ca : P molar ratio: 1.67) system using pump 1 (P1) and pump $2(\mathrm{P} 2)$, respectively (Figure 2). The $\mathrm{pH}$ of both the $\mathrm{Ca}^{2+}$ and $\mathrm{PO}_{4}{ }^{3-}$ ion solutions prior to the reaction, was kept at $\mathrm{pH} 10$. $5.0 \mathrm{~mL}$ and $15.0 \mathrm{~mL}$ of ammonium hydroxide was added to calcium nitrate (500 $\mathrm{mL})$ and diammonium hydrogen phosphate solutions $(500 \mathrm{~mL})$, respectively. Both reagent solutions were pumped at $20 \mathrm{~mL} \mathrm{~min}^{-1}$, to meet at a $1 / 16$ inch Polyflon ${ }^{\mathrm{TM}} \mathrm{T}$ piece through a 1/8 inch Polyflon ${ }^{\mathrm{TM}}$ straight union reducer (D6-D1/8”, PFA).

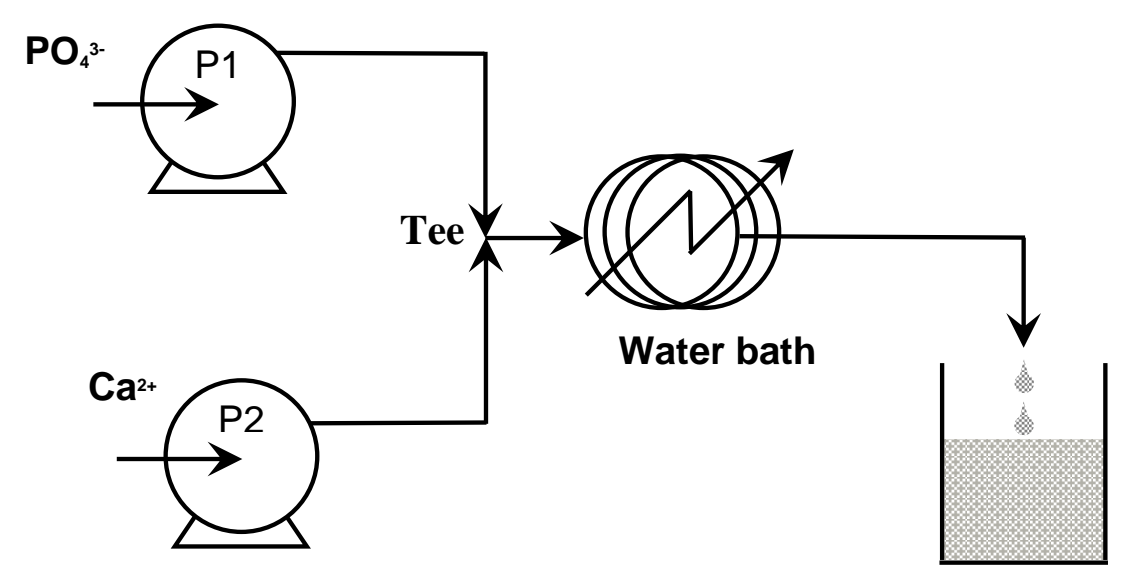

Nanoparticle Slurry 
Fig. 2 Design for two pump (P1, P2) plastic flow system used for the synthesis of pure and surface modified nanohydroxyapatite in which a Tee piece mixer was used and a water bath used for a heat exchanger Key: $\mathrm{P}=$ pump.

This initial mixture then passed through $16 \mathrm{~m}$ long 1/16" Polyflon ${ }^{\mathrm{TM}}$ PTFE tubing coil (ID4.0 mm x OD6.0 mm) located in a heating bath $(\mathrm{H})$ containing $10 \mathrm{~L}$ water at the desired temperature $\left(70{ }^{\circ} \mathrm{C}\right)$. The white aqueous milky suspension was collected in a beaker at the exit point and the solids were quickly recovered by centrifugation at $4500 \mathrm{rpm}$ for 10 minutes (note: it is important not to leave the products for too long in the liquor as they may continue to react). The supernatant was then quickly removed and wet solid residue was briefly redispersed in deionized water using a vortex mixer (VWR model VM-300) for 5 minutes, followed by two further centrifugation and washing cycles. The wet residue obtained was freeze-dried using a VirTis Genesis Pilot Lyophilizer 35XL (SP Scientific, UK) at $0.3 \mathrm{~Pa}$ for 24 hours. The product obtained after freeze-drying was a fine free flowing white powder with $88 \%$ yield.

\subsubsection{Synthesis of surface modified hydroxyapatite:}

The surface modified hydroxyapatites were obtained following a similar procedure as for pure nano-HA, except the calcium containing precursor additionally contained the appropriate amount of $(0.05 \mathrm{M})$ surface agent. Resulting nanopowders were termed PVA-HA (polyvinyl alcohol-hydroxyapatite), A-HA (adipic acidhydroxyapatite), C-HA, (citric acid-hydroxyapatite), VPA-HA (vinylphosphonic acid-hydroxyapatite) and MA-HA (methacrylic acid-hydroxyapatite). 


\subsection{Characterisation Methods}

\subsubsection{Elemental Analysis}

X-ray photoelectron spectroscopy (XPS) analysis of the nano-HA was carried out using a Thermo Scientific K-Alpha XPS. A monochromated Al K-alpha source $(\mathrm{E}=$ $1486.6 \mathrm{eV}$ ) was used with maximum power of $72 \mathrm{~W}$. X-rays were microfocused at source to give a spot size on the sample in the range 30 to $400 \mu \mathrm{m}$. The monochromator comprised of a single toroidal quartz crystal set in a Rowland circle with a radius $250 \mathrm{~mm}$. The vacuum chamber pressure was set at $3 \times 10^{-8}$ Torr. The spectra were collected at an energy of $150 \mathrm{eV}$ for survey scans and at $50 \mathrm{eV}$ for high resolution regions. A 128 channel position sensitive detector was used. The binding energy scale was calibrated by a C 1 s peak at $285 \mathrm{eV}$ and the spectral intensity of the

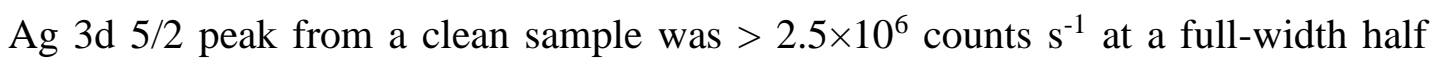
maximum (FWHM) of $1 \mathrm{eV}$. The XPS spectra were processed using the standard supplied “Casa” XPS software package.

\subsubsection{Transmission Electron Microscopy}

A JEOL JEM-1200EX II Transmission Electron Microscope (TEM) was used to produce micrographs. Digital images were taken with a side mounted AMT 2K, high sensitivity digital camera (Debens, East Grinstead, UK). A small amount of nanoHA ( $10 \mathrm{mg})$ was dispersed in $10 \mathrm{~mL}$ methanol (Merck, Darmstadt, Germany) and then placed in an ultrasonic water bath (model USC100T, VWR, East Grinstead, UK) for 2 minutes to yield a dilute suspension. Just a few drops of the resulting 
suspension were deposited on a carbon-coated copper TEM grid (Agar Scientific, Stansted, UK). This grid was allowed to dry in air at room temperature, before inserting it into the TEM. To estimate particle size distributions, the freely-available "Image J" software was used to measure the dimensions of 200 particles of nanoHA, spread over several micrographs.

\subsubsection{Powder X-ray Diffraction}

A Bruker AXS D4 Endeavour X-ray Diffractometer (XRD) was used to investigate the crystal structure of the nano-HA. XRD Spectra were collected in the $2 \theta$ range of 5 to $80^{\circ}$ with a step increment of $0.05^{\circ}$ and a step time of $2 \mathrm{~s}$ using $\mathrm{Cu}-\mathrm{K} \alpha$ radiation $(\lambda=1.5406 \AA)$. The standard supplied "DIFFRACplus Eva" software package was used to compare the XRD spectra with the standard reference pattern for HA.

\subsubsection{Specific Surface Area}

Determinations of specific surface area by the BET $\mathrm{N}_{2}$ adsorption method were made using a Micromeritics ASAP 2420 analyser. Sample tubes were washed with methanol and dried overnight at $100{ }^{\circ} \mathrm{C}$ in an oven. Prior to the $\mathrm{N}_{2}$ adsorption experiment, the samples of nano-HA were weighed and degassed under vacuum for 12 hours at $180{ }^{\circ} \mathrm{C}$. After degassing, the samples were weighed again: this was the mass used in the calculation of specific surface area.

\subsubsection{Fourier Transform Infrared (FTIR)Spectroscopy}


The chemical and structural properties of the nano-HA were probed using a Nicolet $6700^{\mathrm{TM}}$ FTIR spectrometer (Thermo Nicolet, UK). A photo-acoustic sampling (PAS) accessory (MTech PAS cell) was used in conjunction with FTIR, which permitted analysis of neat samples without the need of further sample preparation (e.g. grinding with $\mathrm{KBr}$ and pressing into a transparent disc). The sample chamber was purged with helium gas. The spectra were collected by accumulating 256 number of scans, in mid-IR range (4000 to 400) $\mathrm{cm}^{-1}$ at $4 \mathrm{~cm}^{-1}$ resolution. A background spectrum was collected using a carbon black film.

\subsubsection{Zeta Potential Measurement}

Zeta potential was determined using a Malvern Instruments Zetasizer operated in backscatter mode $\left(173^{\circ}\right)$. The measurements were carried out using an electrophoretic technique in which the sample slurry produced by the CPFS process (solid content $\sim 1 \mathrm{vol} \%$ ). A neat disposable zeta cell was used as a measurement chamber for particle analysis. Measuring electrophoretic mobility in the applied electric field, was used to assess colloidal stability of the dispersed particles. The described values for zeta potential are the average of three repeat measurements.

\section{Results and Discussions}

\subsection{Transmission Electron Microscopy}

Transmission electron microscope images of pure HA (ungrafted hydroxyapatite) samples synthesized at $70{ }^{\circ} \mathrm{C}$ in five minutes residence time via continuous plastic 
flow synthesis (Figure 2), confirmed that rod like crystallites had been obtained. The particles had an average length of $c a .85 \pm 15 \mathrm{~nm}$ (200 particles sampled) and average width of $15 \pm 5 \mathrm{~nm}$ as shown in Figures 3 (a) and (b). In comparison, TEM images of surface grafted hydroxyapatite, were also recorded; methacrylic acid modified HA rods possessed small lengths of $c a .25 \pm 5 \mathrm{~nm}$ (200 particles sampled) and widths of $c a .7 \pm 2 \mathrm{~nm}$ as shown in Figures 4 (a) and (b). On the other hand, vinylphosphonic and adipic acid based HA particles possessed a slightly larger particle size of $c a .35 \pm 5 \mathrm{~nm}$ (200 particles sampled) along the longest axis and of ca. $7 \pm 2 \mathrm{~nm}$ along the smaller axis as shown in Figures 4 (c) to (f).
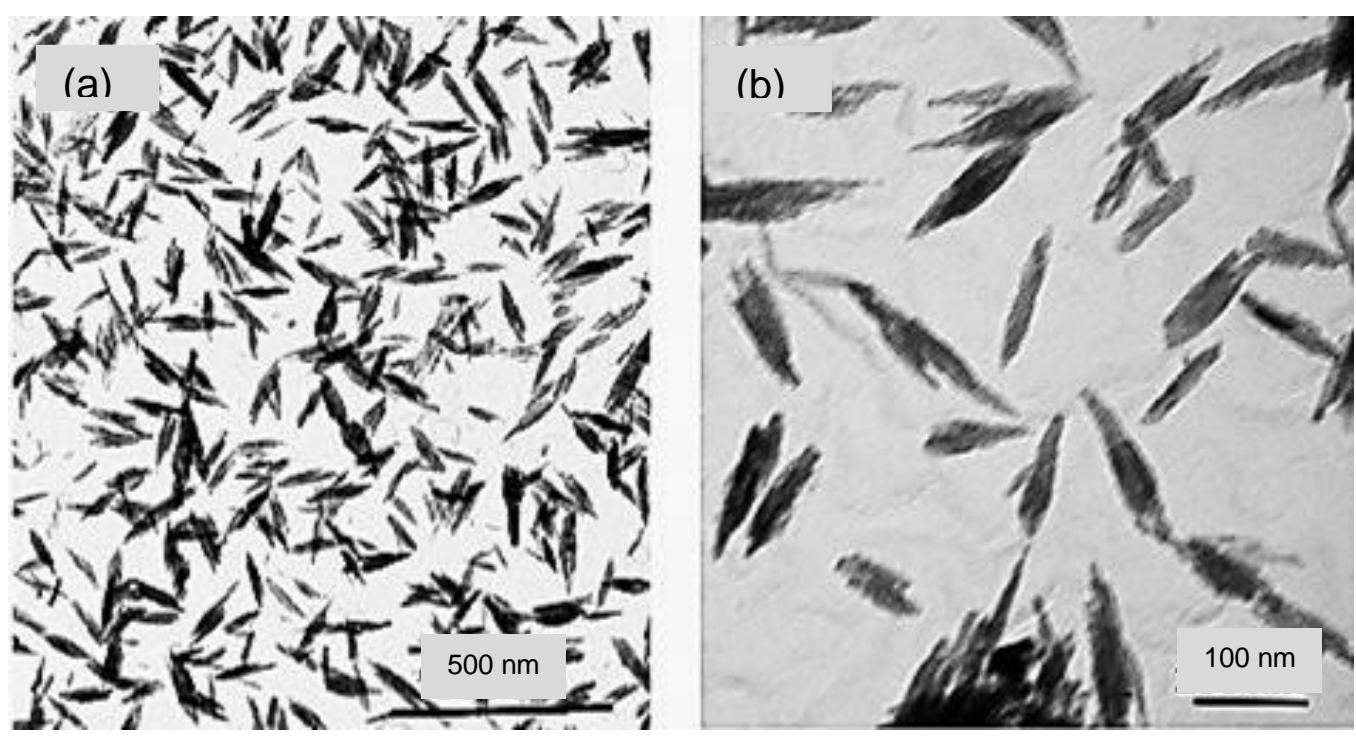

Fig. 3 Transmission electron microscope images of hydroxyapatite nano-rods made at $70{ }^{\circ} \mathrm{C}$ in five minutes residence time via CPFS with bar size shown below numerical boxes; (a) $=500 \mathrm{~nm},(b)=100 \mathrm{~nm}$. 

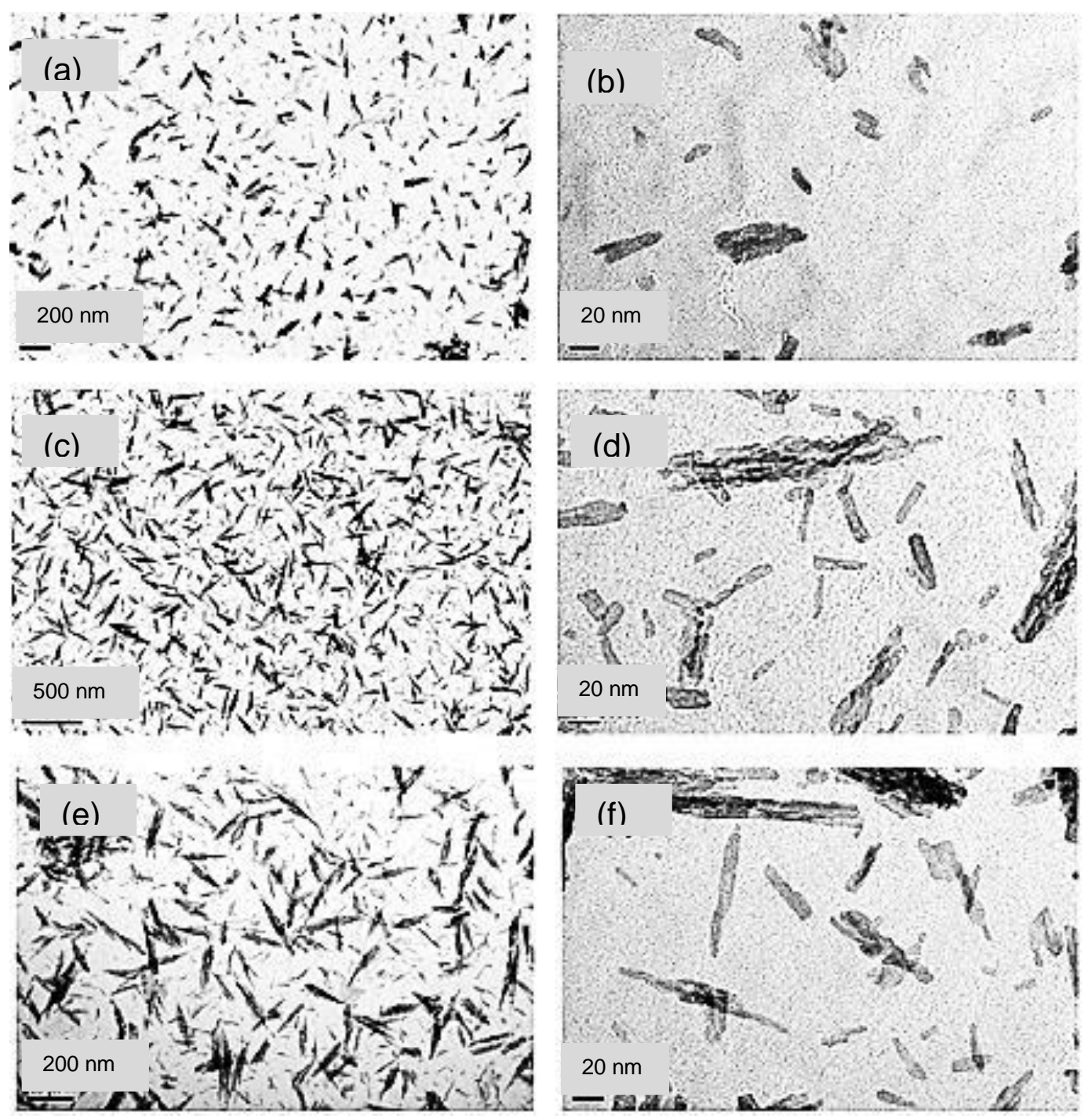

Fig. 4 Transmission electron microscope images of surface modified hydroxyapatite nano-rods made at $70{ }^{\circ} \mathrm{C}$ in five minutes via CPFS (a,b) methacrylic acid modified hydroxyapatite, $(\mathrm{c}, \mathrm{d})$ vinyphosphonic acid modified hydroxyapatite and $(\mathrm{e}, \mathrm{f})$ adipic acid modified hydroxyapatite with bar sizes shown below each numerical box (a) and $(e)=200 \mathrm{~nm},(\mathrm{c})=500 \mathrm{~nm}$, and (b), (d) and (f) bar $=20 \mathrm{~nm}$. 


\subsection{BET Surface Area Analysis}

BET surface area measurements of as-precipitated HA made at $70{ }^{\circ} \mathrm{C}$ via continuous flow synthesis, typically possessed a BET surface area of $195 \mathrm{~m}^{2} \mathrm{~g}^{-1}$. Whilst surface modified PVA-HA (polyvinyl alcohol), A-HA (adipic acid), C-HA, (citric acid), VPA-HA (vinylphosphonic acid) and MA-HA (methacrylic acid) synthesized under the same conditions as unmodified HA, possessed BET surface areas of 143, 208, 201, 225 and $231 \mathrm{~m}^{2} \mathrm{~g}^{-1}$, respectively, as shown in Figure 5.

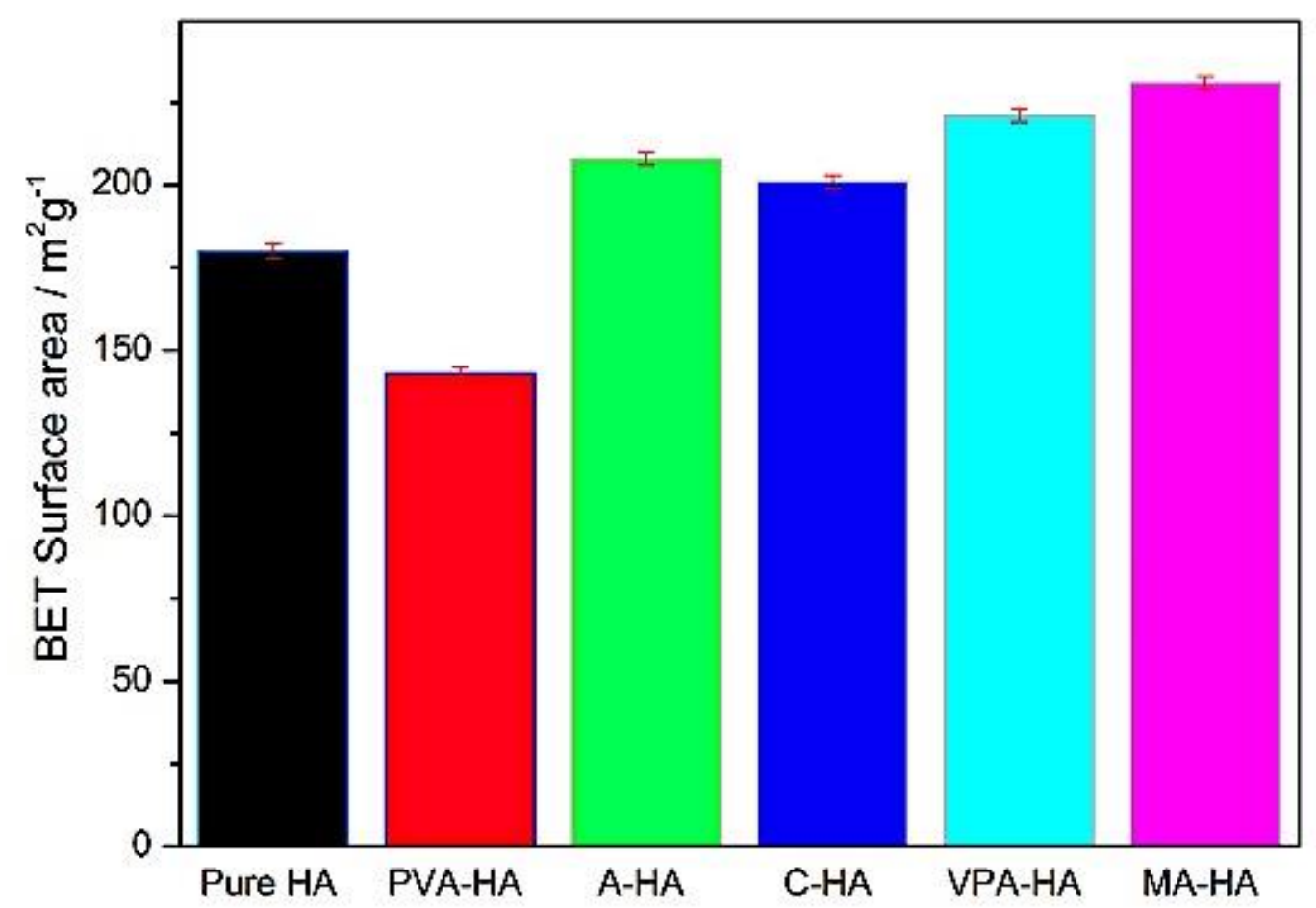

Fig. 5 BET surface area analysis of pure HA, surface modified PVA-HA (polyvinyl alcohol), A-HA (adipic acid), C-HA, (citric acid), VPA-HA (vinylphosphonic acid) and MA-HA (methacrylic acid), respectively, made at $70{ }^{\circ} \mathrm{C}$ in five minutes residence time.

\subsection{Zeta Potential Measurements}


The nature and concentration of ions present in the solution, number of ions adsorbed on the particle surfaces and particle surface conditions, affect zeta potential. The measurements were carried using a sample slurry produced by the CPFS process with solid content of $\sim 1 \mathrm{vol} \%$ that was diluted ca. $\mathrm{x} 100$ with water and then placed in an ultrasonic bath for 10 minutes to help disperse the sample. Zeta potential measurements were performed on selected samples to investigate the colloidal stability related to surface charge of the pure HA and surface-modified HA. Zeta potential gives the electrostatic potential of particles, which is directly related to their dispersion stability; the higher the magnitude of zeta potential values, the greater the electrostatic repulsion and, therefore, the higher the colloidal stability of the suspension. At $\mathrm{pH}$ of 12 , the zeta potential value of $-43.8 \mathrm{mV}$ was measured for MA-HA $\left(70{ }^{\circ} \mathrm{C}\right)$ and $-40.6 \mathrm{mV}$ for VPA-HA $\left(70{ }^{\circ} \mathrm{C}\right)$, respectively, which would be expected to stabilize the particles from agglomeration as shown in Figure 6.

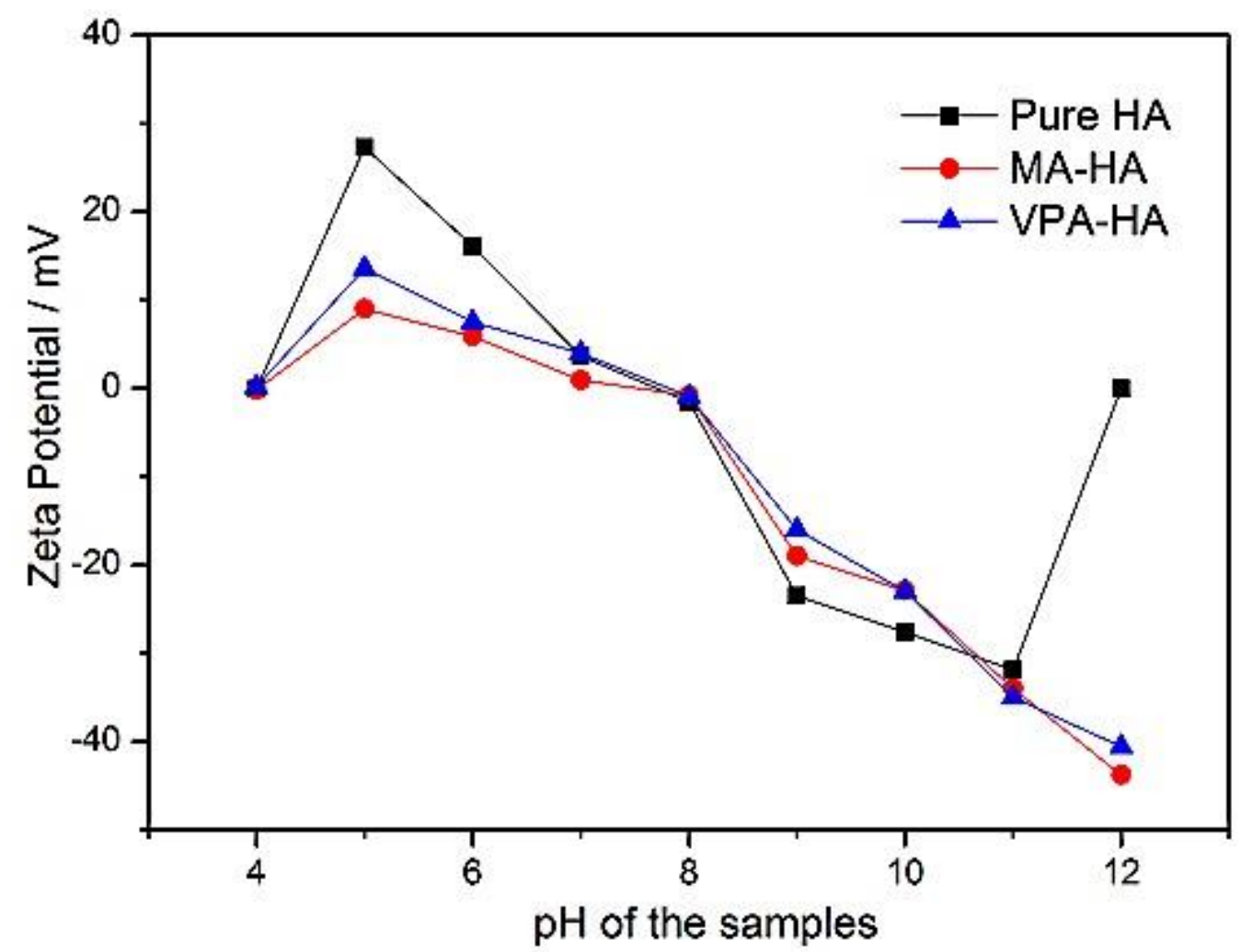


Fig. 6 Zeta potential of pure HA and surface modified methacrylic acid and vinylphosphonic acid-HA samples made at $70^{\circ} \mathrm{C}$ via CPFS.

\subsection{Powder X-ray Diffraction}

The powder X-ray diffraction data of pure HA [supplementary Figure S1 (a)] and surface modified HAs (Figure 7) made via CPFS, all displayed broad peaks, which were typical of an apatite structure. Upon heat-treatment $\left(1000{ }^{\circ} \mathrm{C}\right.$ for 2 hours $)$ in air, the powder X-ray diffraction peaks for the non-functionalized HA sample made via CPFS, became considerably sharper and well resolved and gave a good match to the phase pure hydroxyapatite reference pattern JCPDS [09-432]. No additional peaks due to secondary phases were observed in the XRD data after heat-treatment [as shown in supplementary Figure S1 (b)], thus, this suggests that most likely this material is likely to be close to the $1.67 \mathrm{Ca}: \mathrm{P}$ stoichiometry. 


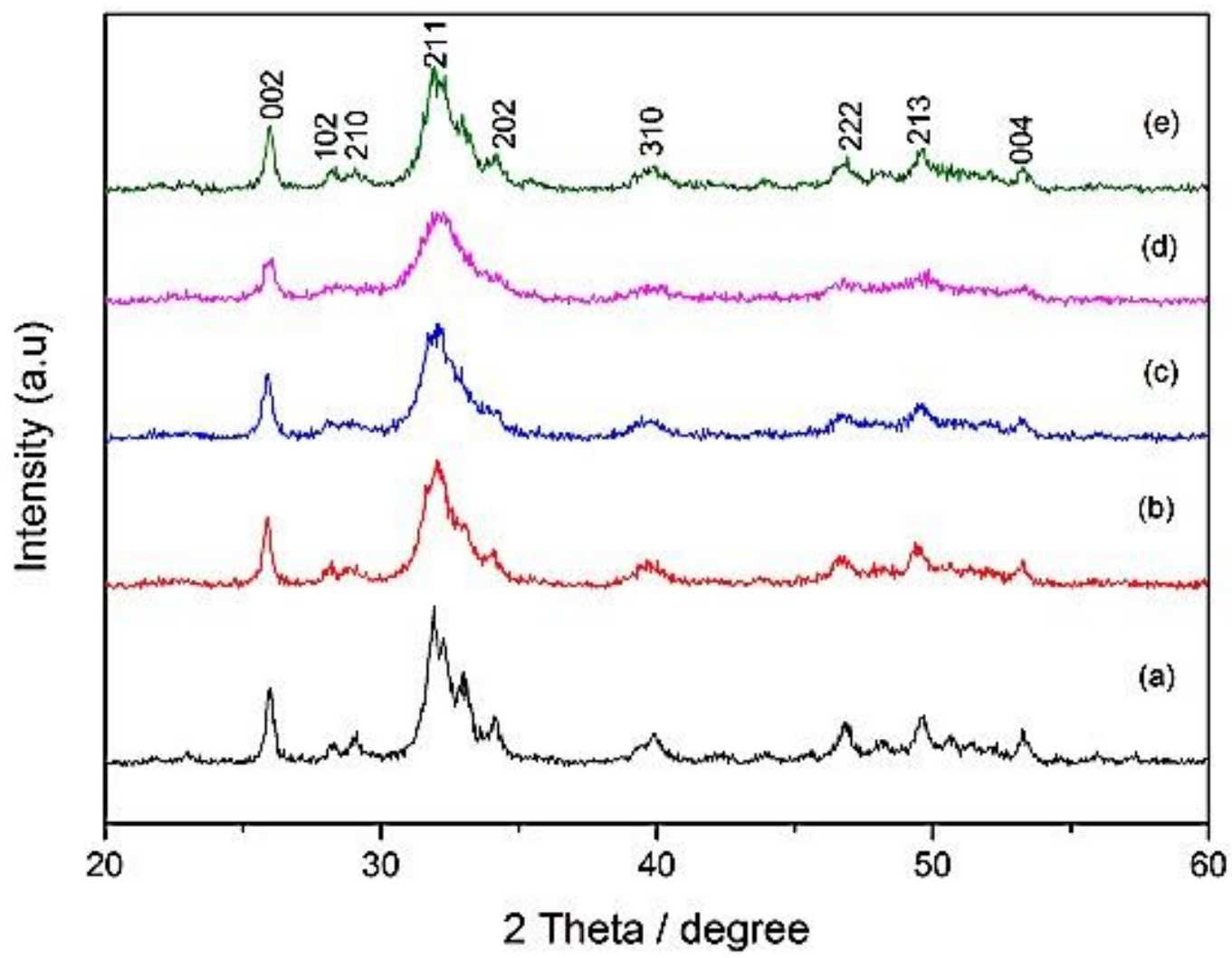

Fig. 7 Powder X-ray diffraction patterns of surface modified hydroxyapatite with (a) $=$ Polyvinylalcohol modified hydroxyapatite $(\mathrm{b})=$ adipic acid modified hydroxyapatite $(\mathrm{c})=$ citric acid modified hydroxyapatite $(\mathrm{d})=$ vinylphosphonic acid modified hydroxyapatite $(\mathrm{e})=$ methacrylic acid modified hydroxyapatite, respectively. All samples were made in a continuous plastic flow system at $70{ }^{\circ} \mathrm{C}$.

\subsection{Fourier Transform Infrared Spectroscopy}

The contribution of the PAS-FTIR technique in the spectrochemical analysis of biomaterials, is an ideal technique where neat samples can be analysed (without the need for extensive sample preparation). It is deemed necessary to purge the sample with helium gas in combination of drying agent by employing magnesium perchlorate. This ensured to keep the system completely dry and free of atmospheric moisture. 
FTIR spectra were obtained using a Nicolet spectrometer in conjunction with a MTech PAS cell. Good quality spectra were obtained at $4 \mathrm{~cm}^{-1}$ resolution averaging 256 scans. Phosphate ions in uncoated HA possessed four vibrational modes, $v_{1}, v_{2}$, $v_{3}$ and $v_{4}$. All these modes are Infrared active and were observed for the spectrum of CPFD made uncoated hydroxyapatite powder (supplementary Figure S2). Peaks in the FTIR spectra at 1093 and $1023 \mathrm{~cm}^{-1}$ corresponded to asymmetric ((P-O) stretching due to phosphate groups, $v_{3}$ band has different sites present at 1093 and $1023 \mathrm{~cm}^{-1}$ The intense $v_{3}$ band is thought to be responsible for totally obscuring the $v_{1}$ carbonate bands whilst peaks at 602 and $560 \mathrm{~cm}^{-1}$ corresponded to the symmetric (P-O) stretch, phosphate $v_{4}$ band is present in the region of 600 and $520 \mathrm{~cm}^{-1}$ and is a usually a well-defined and sharp band phosphate $v_{1}$ bands are observed in the region of 470 and $440 \mathrm{~cm}^{-1}$ and has two sites. These are weak bands, not as strong as the $v_{3}$ and $v_{4}$ bands. Spectral peak at observed at ca. $3569 \mathrm{~cm}^{-1}$ are due to hydroxyl stretch of the $\mathrm{OH}$ group in HA. Carbonate ions can have four vibrational modes, three of which are observed in the infrared spectrum, presence of carbonate groups can be confirmed by the spectral bands occupying two different sites: peaks in the region of 1650 to $1300 \mathrm{~cm}^{-1}$ which are due to $v_{3}$ vibrational mode carbonate ion and the peak at $873 \mathrm{~cm}^{-1}$ is due to the $v_{2}$ vibrational mode.[ref a Rehman IU., \& Bonfield, W. (1997). Characterization of hydroxyapatite and carbonated apatite by photo acoustic FTIR spectroscopy.. J Mater Sci Mater Med, 8(1), 1-4. Retrieved from http://www.ncbi.nlm.nih.gov/pubmed/15348834]

For methacrylic acid and vinylphosphonic acid surface modified samples, which contain $\mathrm{C}=\mathrm{C}$ bonds, a peak for $\mathrm{C}=\mathrm{C}$ stretching was observed at $\sim 1640 \mathrm{~cm}^{-1}$. In the FTIR data for the samples with carboxylates, there were additional peaks due to 
symmetric and asymmetric (C-O) stretching in the carboxylate groups, centered at ca. 1433, 1460, and $1531 \mathrm{~cm}^{-1}$. The FTIR spectrum of the polyvinylalcohol modified hydroxyapatite had a very large peak centered at ca. $3420 \mathrm{~cm}^{-1}$ corresponding to the extensive $(\mathrm{O}-\mathrm{H})$ groups of the polyvinylalcohol $\mathrm{OH}$ groups. IR can you tell me the peak at $750 \mathrm{~cm}-1$ for the same FTIR spectrum? Can we mention its rather intense for this one?[JAWWAD WILL CHECK THIS ANEELA]

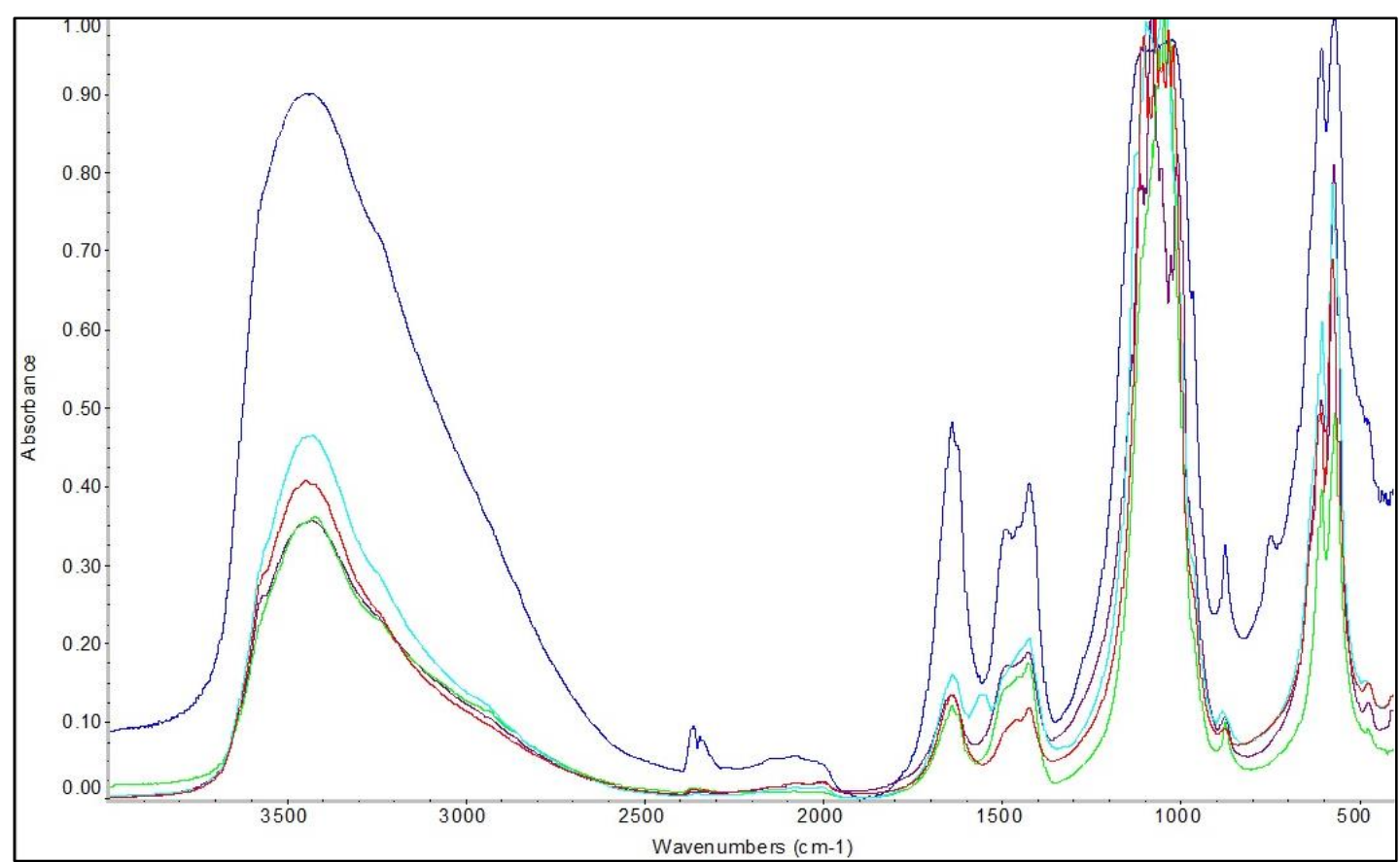

Fig. 8 FTIR Spectra of surface modified hydroxyapatite with (a) = polyvinylalcohol modified hydroxyapatite (deep blue with intense $\mathrm{OH}$ peak), (b) = adipic acid modified hydroxyapatite (red), (c) = citric acid modified hydroxyapatite(light blue), (d) = vinyphosphonic acid modified hydroxyapatite(green), (e) = methacrylic acid modified hydroxyapatite (black) [largely superimposed on green plot], respectively. All samples were made in a continuous plastic flow system at $70{ }^{\circ} \mathrm{C}$.

\subsection{X-ray Photoelectron Spectroscopy}

\subsection{X-ray Photoelectron Spectroscopy}


XPS analysis of VPA-HA sample made at $70{ }^{\circ} \mathrm{C}$, revealed that the ratio $\mathrm{Ca} / \mathrm{P}$ was (1.66), making it closely matching to stoichiometric value in phase pure HA (XPS survey spectrum shown in supplementary figure S3), whilst it was observed that in surface modified HAs, the Ca:P molar ratio decreased to ca. 1.34 due to the addition of organic modifiers (Table S2). This is clearly suggests that some of the ligands are replacing near surface inorganic phosphates.

The deconvoluted spectra for $\mathrm{Ca}, \mathrm{P}$, and $\mathrm{O}$ in sample VPA-HA, are presented in Figure 9. The Ca 2p spectrum in Figure 9 (a), could be resolved into two peaks for Ca $2 p_{3 / 2}$ and $2 p_{1 / 2}$ (two spin-orbit pairs) at 347.4 and $351.3 \mathrm{eV}$, respectively, which are from the calcium in hydroxyapatite. These peaks are shown in Figure 9 (b); the phosphorus $2 \mathrm{p}$ peak can also be deconvoluted into two peaks with a spin orbit splitting for $\mathrm{p}_{1 / 2}$ and $\mathrm{p}_{3 / 2}$ levels, with binding energy of 134.2 and $133.4 \mathrm{eV}$ (much of the literature suggests this as a single peak), respectively ${ }^{36-38}$. Figure 9 (c), depicts the core level XPS spectrum of $\mathrm{O} 1 \mathrm{~s}$ and the peaks at $531.5 \mathrm{eV}$ [assigned to oxygens in hydroxy $\left(\mathrm{OH}^{-}\right)$and inorganic phosphate groups $\left.\left(\mathrm{PO}_{4}{ }^{3-}\right)\right]$ and $532.1 \mathrm{eV}$ (oxygens in adsorbed water) and $533.6 \mathrm{eV}$ (due to oxygens in the VPA organic species). XPS data for the carbon 1s region is provided as supplementary information (Figure S4) and shows binding energies in the range 285.0 to $285.9 \mathrm{eV}$ assigned to the $\mathrm{sp}^{2}$ carbons of the vinyl phosphonate ligand as well as background adventitious (C-O) carbons (at higher binding energies with a weak peak centred at ca. $288 \mathrm{eV}$ ) ${ }^{39,40}$. 

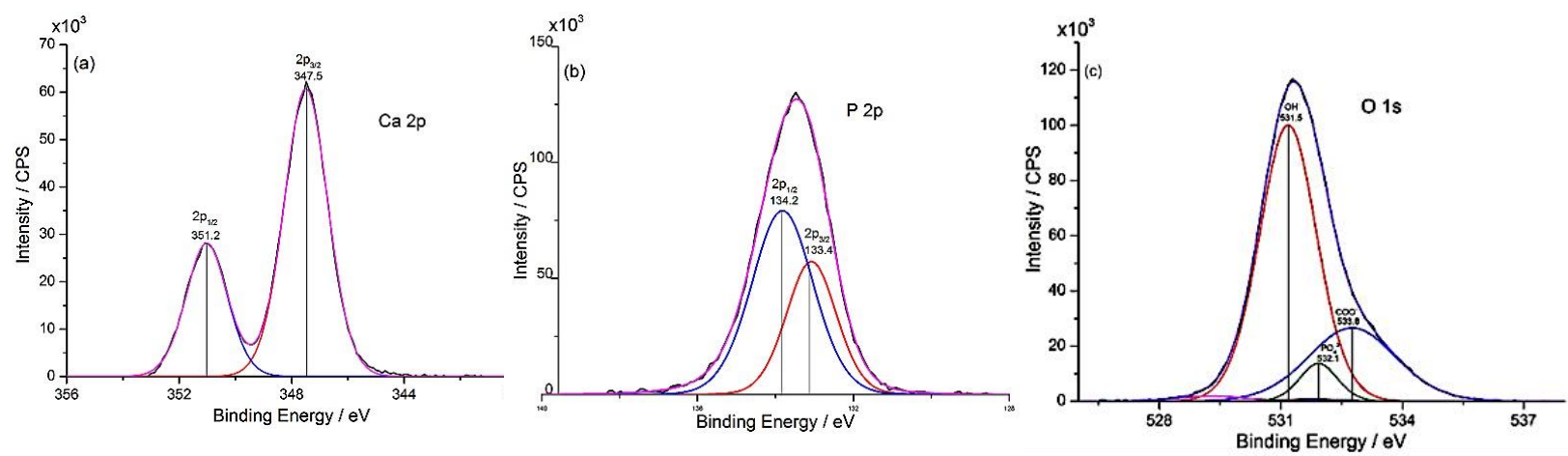

Fig. 9 XPS spectra showing (a) Ca 2p, (b) P 2p and (c) O 1s peaks, respectively, for sample VPA-HA was made in a continuous plastic flow system at $70^{\circ} \mathrm{C}$.

\subsection{Discussion}

In the present work, it was observed that the properties of the precipitated material e.g., surface area and particle morphology, depended mainly on the type of organic surface modifying agents. Organic agents are often used to avoid agglomeration of nanoparticles and allow control of particle growth and formation, for the application of many nanoparticles depends upon the particle being dispersed in an appropriate medium. A dispersion of nanoparticles in solvents generally occurs due to steric (or electrostatic) stabilization from the organic capping agents ${ }^{39}$.

Hydroxyapatite or similar inorganic nanomaterials often possess high affinity for polar organic molecules of organic acids and can form chemical bonds with them. The adsorption capacity of these organic agents on a hydroxyapatite surface, depends on polarization and coordination ability. Negatively charged carboxyl and hydroxyl groups in organic agents can affect particle morphology by their ability to 
bind with calcium ions. Electrostatic interactions take place between cationic sites in the HA mineral and the anionic groups in the complexing agents. As the amount of complexing agent increases, it may lead to a great number of nuclei for HA growth that may in turn, give smaller crystal sizes ${ }^{40}$. The suggested mechanism may have been accompanied by a slight decrease in c parameter (using values extracted from XRD data) with reducing crystallite size (see supplementary Table S1) ${ }^{9}$. The additional surface $\mathrm{P}-\mathrm{OH}$ groups through modification in the literature, can give improved dispersions of nanoparticles (because of higher electrostatic repulsion compared to unmodified ones), that can provide a suitable environment for protein adsorption ${ }^{2,41}$. The surface functionalized nano-HAs herein, with remarkably high surface areas $\left(>200 \mathrm{~m}^{2} \mathrm{~g}^{-1}\right)$ and small particle sizes (typically $>25 \mathrm{~nm}$ ) compared to that reported in the literature, may open up potential applications for use in injectable bioceramics or as a suspension spray feedstock to make bioactive coatings on metallic implants, or as hard fillers in dental cements and biomedical nanocomposites. In further research, the authors showed that the surface area could be even further modified using different synthesis temperatures (see supplementary figure S5, which describes more information about surface area vs reaction temperature in the CPFS). In particular, the high surface are of these nanomaterials should lead to them showing enhanced protein adsorption and cell adhesion during cell-substrate interaction upon implantation ${ }^{42}$. Thus, enhanced protein adsorption or cell interactions ${ }^{43}$ on the on high surface area nano-HA particles (or materials with nanometre topography), might be expected to enhance or certainly alter bone growth rates. Additionally, in case of $\mathrm{HA}$, for a grain size $>100 \mathrm{~nm}$, these materials sometimes exhibit insufficient apposition to bone, leading to implant failure. Most importantly, use of the high surface area surface modified nanoparticles, can be 
exploited to improve interfaces between cells and implants by altering the chemical, biological and mechanical properties ${ }^{6}$, with applications in bone repair, such as spinal fusion ${ }^{44}$ and for apoptotic studies on cancer cells ${ }^{45}$.

\section{Conclusions}

The synthesis of surface-modified HA for a range of surface modifiers, was achieved in 5 minutes in a continuous flow reaction at $70{ }^{\circ} \mathrm{C}$ for the first time. Use of both surface agents as well as an elevated temperature, resulted in the generation of very small particles. Clearly, in comparison to the literature, when much higher temperatures are used for the synthesis of HA in flow (where the particles tend to grow larger), it can be concluded that the temperature of $70{ }^{\circ} \mathrm{C}$ meant that Ostwald ripening effects were not so dominant and particles could remain small. Surface modification reactions, resulted in the production of nanoscale HA crystals that could be readily dispersed in a liquid phase and that possessed remarkably high surface areas. These fine, highly dispersed nanoparticles might certainly be of interest as injectable bioceramic materials or as use in nano-biocomposites.

\section{Acknowledgements}

The Islamic Development Bank is thanked for providing the financial support. Thanks to Dr Chris Tighe and members of the Darr group for support advise during developing a plastic flow reactor. The authors are grateful to Dr. Rob Palgrave and Dr. Josie Goodall for their assistance with XPS analyses

\section{TOC GRAPHIC}



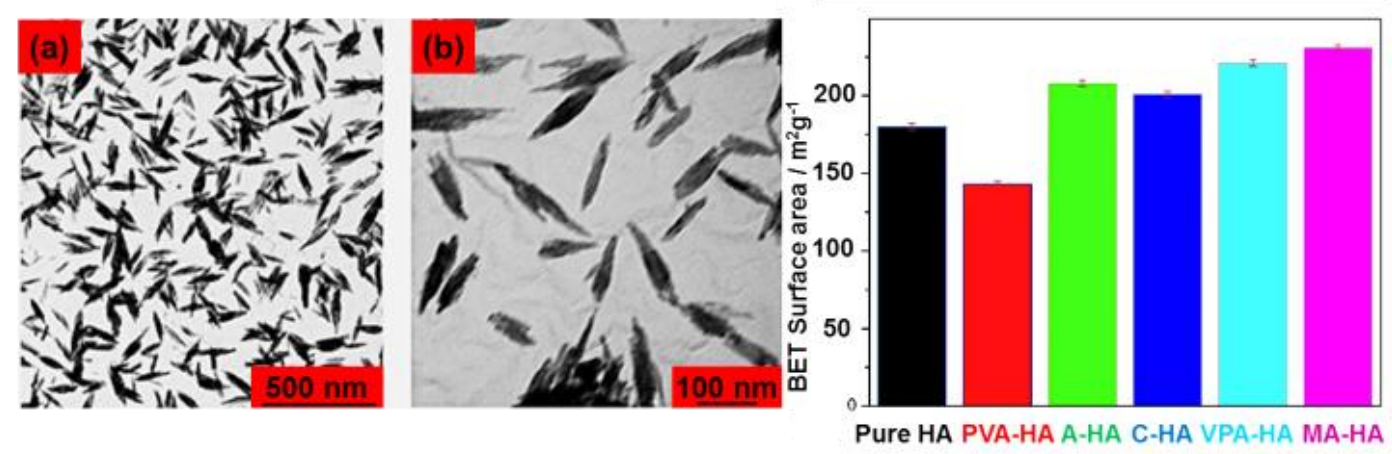

\section{References}

(1) Wei, G.; Ma, P. X. Structure and Properties of Nano-Hydroxyapatite/Polymer Composite Scaffolds for Bone Tissue Engineering. Biomaterials 2004, 25, 4749-4757.

(2) Choi, H. W.; Lee, H. J.; Kim, K. J.; Kim, H.-M.; Lee, S. C. Surface Modification of Hydroxyapatite Nanocrystals by Grafting Polymers Containing Phosphonic acid Groups. J. Colloid Interface Sci. 2006, 304, 277281.

(3) Khan, A.; Ahmed, Z.; Edirisinghe, M.; Wong, F.; Rehman, IU. Preparation and Characterization of a Novel Bioactive Restorative Composite Based on Covalently Coupled Polyurethane-Nanohydroxyapatite Fibres. Acta Biomater. 2008, 4, 1275-1287.

(4) Domingo, C.; Arcís, R.; Osorio, E.; Osorio, R.; Fanovich, M. A.; Rodríguez-Clemente, R.; Toledano, M. Hydrolytic Stability of Experimental Hydroxyapatite-Filled Dental Composite Materials. Dent. Mater. 2003, 19, 478-486.

(5) Sadat-Shojai, M.; Atai, M.; Nodehi, A.; Khanlar, L. N. Hydroxyapatite Nanorods as Novel Fillers for Improving the Properties of Dental Adhesives: Synthesis and Application. Dent. Mater. 2010, 26, 471-482.

(6) Arcís, R. W.; López-Macipe, A.; Toledano, M.; Osorio, E.; Rodríguez-Clemente, R.; Murtra, J.; Fanovich, M. A.; Pascual, C. D. Mechanical Properties of Visible Light-Cured Resins Reinforced with Hydroxyapatite for Dental Restoration. Dent. Mater. 2002, 18, 49-57. 
(7) Willems, G.; Lambrechts, P.; Braem, M.; Celis, J.-P.; Vanherle, G. A Classification of Dental Composites According to their Morphological and Mechanical Characteristics. Dent. Mater. 1992, 8, 310-319.

(8) Giannini, M.; Soares, C. J.; de Carvalho, R. M. Ultimate Tensile Strength of Tooth Structures. Dent. Mater. 2004, 20, 322-329.

(9) Puvvada, N.; Panigrahi, P. K.; Pathak, A. Room Temperature Synthesis of Highly Hemocompatible Hydroxyapatite, Study of their Physical Properties and Spectroscopic Correlation of Particle Size. Nanoscale 2010, 2, 2631-2638.

(10) Hlady, V.; Füredi-Milhofer, H. Adsorption of Human Serum Albumin on Precipitated Hydroxyapatite. J. Colloid Interface Sci. 1979, 69, 460-468.

(11) Schaad, P.; Thomann, J.-M.; Voegel, J.-C.; Gramain, P. Adsorption of Neutral and Anionic Polyacrylamides on Hydroxyapatite and Human Enamel: Influence on the Dissolution Kinetics. J. Colloid Interface Sci. 1994, 164, 291-295.

(12) Haque, S.; Rehman, IU.; Darr, J. A. Synthesis and Characterization of Grafted Nanohydroxyapatites using Functionalized Surface Agents. Langmuir 2007, 23, 6671-6676.

(13) D'Andre, S. C.; Fadeev, A. Y. Covalent Surface Modification of Calcium Hydroxyapatite using N-Alkyl-And N-Fluoroalkylphosphonic Acids. Langmuir 2003, 19, 7904-7910.

(14) Borum-Nicholas, L.; Wilson, O. Surface Modification of Hydroxyapatite. Part I. Dodecyl Alcohol. Biomaterials 2003, 24, 3671-3679.

(15) Vega, E. D.; Narda, G. E.; Ferretti, F. H. Adsorption of Citric Acid from Dilute Aqueous Solutions by Hydroxyapatite. J. Colloid Interface Sci. 2003, 268, 37-42.

(16) Borum, L.; Wilson, O. Surface Modification of Hydroxyapatite. Part II. Silica. Biomaterials 2003, 24, 3681-3688.

(17) Tanaka, H.; Futaoka, M.; Hino, R.; Kandori, K.; Ishikawa, T. Structure of Synthetic Calcium Hydroxyapatite Particles Modified with Pyrophosphoric Acid. J. Colloid Interface Sci. 2005, 283, 609-612.

(18) Tanaka, H.; Futaoka, M.; Hino, R. Surface modification of calcium hydroxyapatite with pyrophosphoric acid. J. Colloid Interface Sci. 2004, 269, 358-363.

(19) Raynaud, S.; Champion, E.; Bernache-Assollant, D.; Thomas, P. Calcium Phosphate Apatites with Variable $\mathrm{Ca} / \mathrm{P}$ Atomic Ratio I. Synthesis, Characterisation and Thermal Stability of Powders. Biomaterials 2002, 23, 1065-1072.

(20) Ahn, E. S.; Gleason, N. J.; Nakahira, A.; Ying, J. Y. Nanostructure Processing of Hydroxyapatite-Based Bioceramics. Nano Lett. 2001, 1, 149153.

(21) Rodriguez-Lorenzo, L.; Vallet-Reg1, M.; Ferreira, Fabrication of Hydroxyapatite Bodies by Uniaxial Pressing from a Precipitated Powder. J. Biomaterials 2001, 22, 583-588.

(22) Jokanović, V.; Uskoković, D. Calcium Hydroxyapatite Thin Films on Titanium Substrates Prepared by Ultrasonic Spray Pyrolysis. 2005, 46, 228235.

(23) Hench, L. L.; West, J. K. The Sol-Gel Process. Chem. Rev.1990, 90, 3372. 
(24) Güler, H.; Gündoğmaz, G.; Kurtuluş, F.; Çelik, G.; Gacanoğlu, Ş. Solid State Synthesis of Calcium Borohydroxyapatite. Solid State Sci. 2011, 13, 1916-1920.

(25) Darr, J.; Guo, Z.; Raman, V.; Bououdina, M.; Rehman, IU. Metal Organic Chemical Vapour Deposition (MOCVD) of Bone Mineral like Carbonated Hydroxyapatite Coatings. Chem. commun. 2004, 696-697.

(26) Wang, Y. J.; Lai, C.; Wei, K.; Chen, X.; Ding, Y.; Wang, Z. L. Investigations on the Formation Mechanism of Hydroxyapatite Synthesized by the Solvothermal Method. Nanotechnology 2006, 17, 4405-4412.

(27) Anwar, A.; Asghar, M. N.; Kanwal, Q.; Kazmi, M.; Sadiqa, A. Low Temperature Synthesis and Characterization of Carbonated Hydroxyapatite Nanocrystals. J. Mol. Struct. 2016, 1117, 283-286.

(28) Pang, Y.; Bao, X. Influence of Temperature, Ripening Time and Calcination on The Morphology and Crystallinity of Hydroxyapatite Nanoparticles. J. Eur. Ceram. Soc. 2003, 23, 1697-1704.

(29) Phillips, M.; Darr, J.; Luklinska, Z.; Rehman, IU. Synthesis and Characterization of Nano-Biomaterials with Potential Osteological Applications. J. Mater. Sci.: Mater. Med. 2003, 14, 875-882.

(30) Lim, G.; Wang, J.; Ng, S.; Chew, C.; Gan, L. Processing of Hydroxyapatite via Microemulsion and Emulsion Routes. Biomaterials 1997, 18, 1433-1439.

(31) Kothapalli, C.; Wei, M.; Legeros, R.; Shaw, M. Influence of Temperature and Aging Time on HA Synthesized by the Hydrothermal Method. J. Mater. Sci.: Mater. Med. 2005, 16, 441-446.

(32) Wang, Y.; Zhang, S.; Wei, K.; Zhao, N.; Chen, J.; Wang, X.

Hydrothermal Synthesis of Hydroxyapatite Nanopowders using Cationic Surfactant as a Template. Mater. Lett. 2006, 60, 1484-1487.

(33) Kim, S.; Ryu, H.-S.; Shin, H.; Jung, H. S.; Hong, K. S. In Situ Observation of Hydroxyapatite Nanocrystal Formation from Amorphous Calcium Phosphate in Calcium-rich Solutions. Mater. Chem. Phys. 2005, 91, 500-506.

(34) Chaudhry, A. A.; Haque, S.; Kellici, S.; Boldrin, P.; Rehman, IU.; Khalid, F. A.; Darr, J. A. Instant Nano-Hydroxyapatite: A Continuous and Rapid Hydrothermal Synthesis. Chem. commun. 2006, 2286-2288.

(35) Mahabole, M.; Aiyer, R.; Ramakrishna, C.; Sreedhar, B.; Khairnar, R. Synthesis, Characterization and Gas Sensing Property of Hydroxyapatite Ceramic. Bull. Mater. Sci. 2005, 28, 535-545.

(36) Costescu, A.; Pasuk, I.; Ungureanu, F.; Dinischiotu, A.; Costache, M.; Huneau, F.; Galaup, S.; Le Coustumer, P.; Predoi, D. Physico-Chemical Properties of Nano-Sized Hexagonal Hydroxyapatite Powder Synthesized by Sol-Gel. Dig. J. Nanomater. Biostruct. 2010, 5, 989-1000.

(37) Lu, H. B.; Campbell, C. T.; Graham, D. J.; Ratner, B. D. Surface Characterization of Hydroxyapatite and Related Calcium Phosphates by XPS and TOF-SIMS. Anal. Chem. 2000, 72, 2886-2894.

(38) Casaletto, M.; Kaciulis, S.; Mattogno, G.; Mezzi, A.; Ambrosio, L.; Branda, F. XPS Characterization of Biocompatible Hydroxyapatite-Polymer Coatings. Surf. Interface Anal. 2002, 34, 45-49.

(39) Lu, A. H.; Salabas, E. e. L.; Schüth, F. Magnetic Nanoparticles: Synthesis, Protection, Functionalization, and Application. Angew. Chem., Int. Ed. 2007, 46, 1222-1244. 
(40) Kwon, K.-Y.; Wang, E.; Chung, A.; Chang, N.; Saiz, E.; Choe, U.-J.; Koobatian, M.; Lee, S.-W. Defect Induced Asymmetric Pit Formation on Hydroxyapatite. Langmuir 2008, 24, 11063-11066.

(41) Thanh, N. T.; Green, L. A. Functionalisation of Nanoparticles for Biomedical Applications. Nano Today 2010, 5, 213-230.

(42) Ben-Nissan, B. Nanoceramics in Biomedical Applications. MRS bulletin 2004, 29, 28-32.

(43) Webster, T. J.; Ergun, C.; Doremus, R. H.; Siegel, R. W.; Bizios, R. Specific Proteins Mediate Enhanced Osteoblast Adhesion on Nanophase Ceramics. J. Biomed. Mater. Res. 2000, 51, 475-483.

(44) Tang, Z. B.; Cao, J. K.; Wen, N.; Wang, H. B.; Zhang, Z. W.; Liu, Z. Q.; Zhou, J.; Duan, C. M.; Cui, F. Z.; Wang, C. Y. Posterolateral Spinal Fusion with Nano - Hydroxyapatite-Collagen/PLA Composite and Autologous Adipose - Derived Mesenchymal Stem Cells in a Rabbit Model. J. Tissue. Eng. Regen. Med. 2012, 6, 325-336.

(45) Yuan, Y.; Liu, C.; Qian, J.; Wang, J.; Zhang, Y. Size-Mediated Cytotoxicity and Apoptosis of Hydroxyapatite Nanoparticles in Human Hepatoma Hepg2 Cells. Biomaterials 2010, 31, 730-740. 